\title{
Cold Spraying of Armstrong Process Titanium Powder for Additive Manufacturing
}

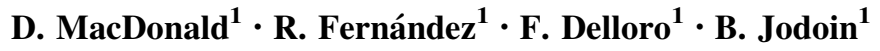

Submitted: 6 July 2016/in revised form: 22 August 2016/Published online: 9 December 2016

(c) ASM International 2016

\begin{abstract}
Titanium parts are ideally suited for aerospace applications due to their unique combination of high specific strength and excellent corrosion resistance. However, titanium as bulk material is expensive and challenging/costly to machine. Production of complex titanium parts through additive manufacturing looks promising, but there are still many barriers to overcome before reaching mainstream commercialization. The cold gas dynamic spraying process offers the potential for additive manufacturing of large titanium parts due to its reduced reactive environment, its simplicity to operate, and the high deposition rates it offers. A few challenges are to be addressed before the additive manufacturing potential of titanium by cold gas dynamic spraying can be reached. In particular, it is known that titanium is easy to deposit by cold gas dynamic spraying, but the deposits produced are usually porous when nitrogen is used as the carrier gas. In this work, a method to manufacture low-porosity titanium components at high deposition efficiencies is revealed. The components are produced by combining low-pressure cold spray using nitrogen as the carrier gas with low-cost titanium powder produced using the Armstrong process. The microstructure and mechanical properties of additive manufactured titanium components are investigated.
\end{abstract}

Keywords additive manufacturing - Armstrong process . cold spray $\cdot$ powder morphology $\cdot$ titanium

D. MacDonald

daniel.macdonald@uottawa.ca

1 University of Ottawa Cold Spray Laboratory, Ottawa, ON, Canada

\section{Introduction}

Titanium is the ninth most abundant element on earth, has one of the highest specific strengths for a pure metal, maintains good properties at elevated temperatures, and has excellent corrosion resistance. However, the high cost to produce titanium components limits its use to high-end applications where cost is not a primary factor, usually in the aerospace, defense, and medical sectors (Ref 1,2$)$. This high cost is the result of two factors: The production of titanium mill product from primary materials requires many costly steps, and its reactivity and poor workability make it difficult to cast, forge, and machine (Ref 1).

Typically, titanium is converted from raw primary materials (such as rutile) to titanium sponge through the Kroll process (Ref 1). It must then be purified through acid leaching and undergo vacuum arc remelting to form an ingot. The latter must then undergo primary fabrication into mill products, casting to a near-net shape (Ref 1), or atomized into powder form. Forging is difficult and expensive, requiring many steps and various heat treatments; only rarely is titanium directly forged into finished components. Casting is also possible but challenging due to the materials' high reactivity to the atmosphere and to the other refractory materials common in the casting process. Near-net shapes can be produced using casting often with a combination of hot isotactic pressing (HIP) and traditional machining, but are limited in scope due to the production costs. As a result of these limitations, components are often produced through traditional manufacturing from large stock, which results in material losses of up to $90 \%$ for aerospace parts which accounts for over $60 \%$ of the final part costs. Even this traditional machining is difficult as titanium has a tendency for seizing and galling (Ref 2). 
Due to these cost factors, far less titanium is used in production applications than expected (Ref 1).

Near-net-shape components using additive manufacturing ( $\mathrm{AM}$ or 3D printing) and powder metallurgy (PM) methods have recently been used to alleviate some of these cost problems (Ref 1-3). AM of metals can be separated into two broad categories: indirect methods, where a binder is used to bond the metal particles and post-processing is used to remove the binder and consolidate the part, and direct methods, where the final part is created directly without a binder (Ref 4). It is possible to fabricate intricate parts with good surface finishes with processes such as electron beam melting (EBM) (Ref 3-5); however, this process is currently limited by a manufacturing rate of $6 \mathrm{~g} /$ min at the very high end for titanium [modified from (Ref $6,7)$ using a density of titanium of $4.51 \mathrm{~g} / \mathrm{cm}^{2}$ (Ref 1)]. This deposition rate leaves much room for improvement. The printed parts also suffer from poor dimensional tolerances and surface finish when compared to machined or cast parts (Ref 8), as well as having a non-uniform grain structure due to uneven melting and heating (Ref 9). The size of these components is also limited to the size of the powder bed and inert environment chamber (Ref 3-5).

In most cases, titanium components produced using AM or PM methods require HIP processing (Ref 3, 10). By simultaneously applying pressure and temperature to the parts, consolidation of the pores is possible. However, HIP processing significantly affects the final component volume and geometry. This must be considered during the design stages and modeling continues to be a great challenge to accurately predict HIP shrinkage for AM and PM parts. Furthermore, the properties of HIP processed parts are usually found to be coarser than desirable and additional heat treatments are required. Lastly, the majority of these methods currently require the use of expensive, gas-atomized powders. As a result of these downsides, AM of titanium is often limited to small, non-structural components with low-quality requirements (Ref 1$)$.

Cold gas dynamic spraying (CGDS) is a solid-state thermal spray process normally used for coatings and repairs. Over two decades of fundamental studies (Ref 1119) have elucidated the theoretical principles of the process, which has led to the development of commercial equipment and applications (Ref 20-23). While the CGDS process has become established in recent years, particularly for repairs (Ref 24-27), it is still in its infancy as an AM process (Ref 28-36). CGDS could be used as a direct process for AM of titanium, taking advantage of the large deposition rates possible with CGDS systems [up to $500 \mathrm{~g} /$ min (Ref 37)]. This rate is an order of magnitude larger than the current fastest powder-based AM technology [83 g/min (Ref 38)]. CGDS process also results in high adhesion to the substrate (Ref 39), which could be used to fabricate extensions on existing parts. Another advantage of the CGDS process is component that is not limited by tray size like in other AM processes.

However, according to the literature, helium or extremely high-pressure and high-temperature nitrogen is required to create dense titanium deposits (Ref 39-45). Schmidt et al. (Ref 13) proposed that the critical velocity for titanium is above $700 \mathrm{~m} / \mathrm{s}$ for adiabatic sheer instability to occur. This may limit the possibility of using this process as fabrication tool due to high cost of equipment and operation. The high temperatures required may also lead to degradation of the properties of the original component if the CGDS process is used to produce extensions of existing parts.

Recent advancements in titanium production have introduced new powder morphology to the market through the Armstrong process (Ref 46, 47). The powder produced through this method has a coral-like morphology, which is very different from commonly used powders in the CGDS process, such as spherical gas-atomized powder, mechanically crushed angular particles, or the titanium sponge morphology created during the Kroll process (Ref 21). Furthermore, the powder produced with the Armstrong process is attractive since it can be produced at a significantly lower cost when compared to traditional spherical powder. Normal spherical powder costs upwards of $110 \mathrm{USD} / \mathrm{kg}$ to produce, while Armstrong powder, which is produced directly from the reduction of $\mathrm{TiCl} 4$ in a continuous liquid loop, costs only 11-24 USD/kg (Ref 48, 49).

It has been shown that the morphology of titanium powder can have an impact on deposition behavior. Wong et al. showed that irregular and sponge titanium morphologies had higher deposition efficiency (DE) when compared to spherical powders (Ref 45). This increase was attributed to a higher particle velocity, as a result of an increase in drag force combined with a lower mass. Wong et al. (Ref 45) also observed higher porosity levels in the coatings deposited with the sponge powder created through the Kroll process, attributed to the internal porosity of the feedstock powder. Yin et al. (Ref 50) have shown that irregular titanium particles may reduce substrate adhesion as a result of torque acting on the particle during impact with the substrate. However, there have been no studies on the CGDS of titanium powders produced by the Armstrong process.

The powder's unique morphology produces excellent compressibility and compaction behavior when used in traditional PM processes, capable of producing compacts with significantly higher green strength and lower porosity than other irregular powders (Ref 46, 48). The particular morphology of the powder should result in a large drag force combined with a lower mass per unit volume when 
compared to spherical particles. As a result, it is possible that less aggressive CGDS parameters may be used to reach high DE and low-porosity deposits.

This work is a preliminary study on the use of unique titanium particle morphology, one produced during production using the Armstrong process (Ref 47), to produce high-density CGDS deposits with low-pressure and lowtemperature nitrogen as propellant gas. The deposition behavior is examined through DE, particle velocity, coating density, and hardness. The understanding of the behavior is further enhanced through particle impact modeling. Lastly, CGDS is used to additively manufacture tensile test samples and heat treatments are done to improve the mechanical properties of the AM components. The combination of the reduced machining costs of AM, the high deposition rates and low operating costs of CGDS, and low-cost powder from the Armstrong process could significantly reduce the overall cost of producing large, near-net-shape, titanium components.

\section{Materials and Methods}

\section{Feedstock Powder}

The feedstock powder used for this study was commercially pure (grade 2$)$ titanium powder ( $<325$ mesh) from Cristal Metals (Cristal US Inc., Woodridge, IL, USA). It is produced using the Armstrong process. The process produces powder particles with unique, low bulk density, "coral-like" morphology as shown in Fig. 1.

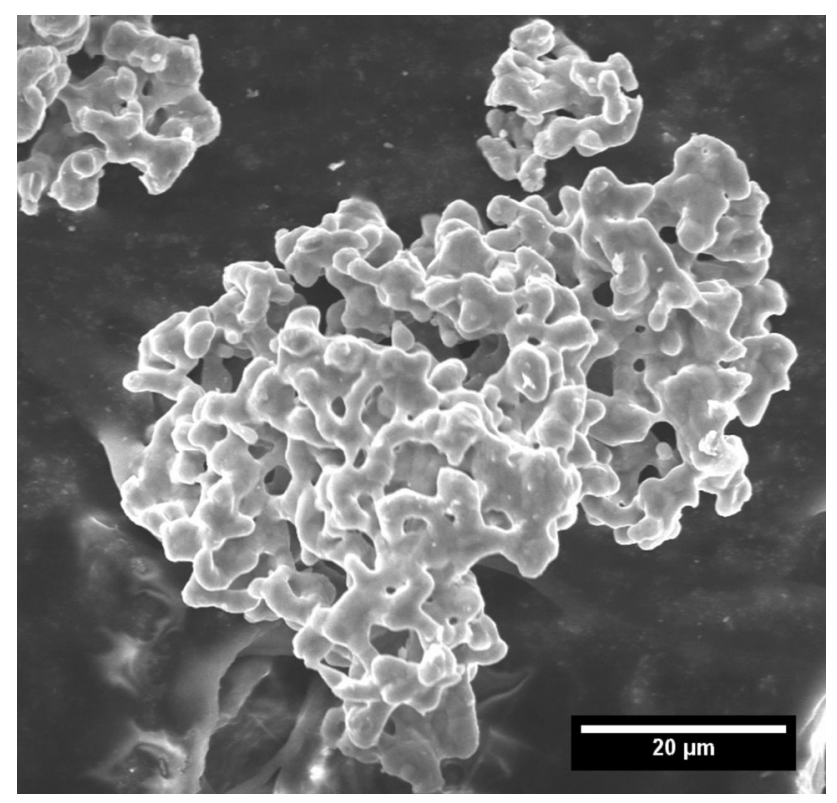

Fig. 1 SEM image of coral-shaped titanium powder produced using the Armstrong process

\section{CGDS Process}

The titanium powder was consolidated using the commercially available SST Series EP Cold Spray System (Centerline Ltd, Windsor, Canada). The system has a maximum operating gas temperature of $550{ }^{\circ} \mathrm{C}$ and a maximum gas pressure of $3.8 \mathrm{MPa}$. A stainless steel de Laval nozzle with a 2-mm-diameter throat, a 120-mm-long diverging section, and an exit diameter of $6.6 \mathrm{~mm}$ was used. Powder was fed downstream of the orifice at a $45^{\circ}$ angle using a commercially available powder feeder from Praxair Surface Technologies (Model 1264, Praxair Surface Technologies, Concord, NH, USA).

In order to investigate the effect of process gas pressure and temperature on the deposition behavior of this powder, the parameters in Table 1 were used. Since densification of this powder in other PM processes requires less energy than with spherical powder, it is envisioned that deposition may be possible at lower ranges of parameters than those discussed in the literature (Ref 13, 39-45). Therefore, a large range of temperatures and pressures were tested in order to understand the behavior of this unique powder morphology during the CGDS consolidation process.

In order to further understand the deposition behavior of single particles, single impact analysis was also completed. This was done by reducing the powder feed rate while holding the other parameters constant in order to see the impact of only one particle at a time on the substrate. For these tests, the substrate was polished commercially pure titanium (grade 2).

\section{Sample Characterization}

As-received powder, single impact tests, and consolidated powders (thick deposits) microstructures were investigated using a scanning electron microscope (EVO-MA10, Zeiss, UK) and an optical microscope (VHX-2000E, Keyence, Canada). In order to quantify porosity level, cross sections of the deposits were stitched together using the VHX-2000 software at a magnification of $200 \times$. The porosity was then quantified through contrast of the optical images using ImageJ software for three cross sections per deposit. Microhardness testing of the deposits was conducted on the cross section of polished samples using a Vickers

Table 1 CGDS parameters during testing

\begin{tabular}{ll}
\hline Parameter & \multicolumn{1}{c}{ Value } \\
\hline Gas nature & Nitrogen \\
Gas pressure & $1.0-3.8 \mathrm{MPa}$ \\
Gas temperature & $100-500{ }^{\circ} \mathrm{C}$ \\
Powder feeder gas flow rate & $1.7 \mathrm{~m}^{3} / \mathrm{h}$ \\
Powder feeder gas nature & Nitrogen \\
Standoff distance & $10 \mathrm{~mm}$ \\
\hline
\end{tabular}


microhardness tester (Struers Duramin-1, Struers Inc., Cleveland, OH, USA) with a 300-g load with a dwell time of $15 \mathrm{~s}$. To avoid the effect of the stress field, the distance between two indentations was kept at $>3$ times the length of the indentation. The reported values are the average of a series of ten indentations for each sample, taken at different areas of the dense center of the deposit. Substrate temperatures were measured using an infrared camera (FLIR E50, FLIR Systems Inc., USA).

\section{Particle Velocity Measurement}

Particle velocity measurements were taken using the ColdSprayMeter (CSM) eVOLUTION (Tecnar Automation Ltd, St-Bruno, Canada). This system uses a continuous $2.4 \mathrm{~W}$ $(\lambda=810 \mathrm{~nm})$ laser with a dual-split photomask in order to perform in-flight diagnostic on individual particles. It provides precise velocity of individual particles during flight. In this study, the velocity measurements were taken at a point $10 \mathrm{~mm}$ downstream from the center of the cold spray nozzle exit. Testing was run for several minutes to ensure the collection of a robust set of data to ensure significant results.

\section{Modeling of Particle Impact Dynamics}

The aim of the modeling work was to demonstrate that powder morphology can have a capital importance on the densification and bonding seen in the CGDS consolidation process. This study shows the densification of the coralshaped titanium powder and compares it to the experimental single impact testing. This study also compares the behavior of the coral-shaped titanium powder versus the behavior of traditional gas-atomized spherical powders through a 2D modeling approach.

Most of the modeling approaches in the field of CGDS deal with spherical particles (Ref 51-57). Few exceptions appeared recently in the literature. A study (Ref 50) simulated the 2D impact of elliptical particles. Another dealt with 3D simulation of pseudo-cylindrical particles (Ref 58). For the current work, the modeling will use 2D particle approximation. A specific image treatment procedure was developed, based on a marker-driven watershed algorithm, implemented in the open-source Simple Morphological Image Library (SMIL) software. First, thresholding of the image was performed to identify the particle, which was used as a mask for the watershed. The segmented image was then treated with an in-house code in order to extract the external perimeter of the image as a sequence of coordinates. The same procedure was applied to the internal porosity. A piecewise linearization algorithm was then applied to simplify the data and thus reduce the number of points. This procedure enabled to import the real cross-sectional morphology of the particles into the finite element software Abaqus/Explicit ${ }^{\circledR}$. The geometries obtained in this way were meshed using bilinear quadrilateral elements within Abaqus.

The modeling physics did not differ from most of the modeling efforts presented in the literature [e.g., (Ref 59, 60) among many others]. The "Mie-Gruneisen" equation of state (EOS), describing material state in the high-pressure domain and shock wave propagation, was used in the Hugoniot formulation,

$p-p_{\mathrm{H}}=\Gamma \rho\left(E-E_{\mathrm{H}}\right)$

where $p$ is the pressure, $\rho$ the density, $E$ the internal energy, $\Gamma=\Gamma_{0} \rho_{0} / \rho, \quad \eta=1-\rho_{0} / \rho, \quad p_{\mathrm{H}}=\rho_{0} c_{0}^{2} \eta /(1-s \eta)^{2}$, $E_{\mathrm{H}}=p_{\mathrm{H}} \eta / 2 \rho_{0}$. Subscript zero refers to a standard reference state. The number of independent parameters sums up to three in the EOS: $\eta, s$ and $c_{0}$. Further details can be found in Antoun et al. (Ref 61).

The widely used Johnson-Cook model (Ref 62) was selected as an empirically based representation of the yield stress. The material parameters were readily available in the literature for titanium (Ref 51,63) which was decisive for the choice of Johnson-Cook model. The model involved strain hardening, strain rate hardening, and thermal softening. The yield stress is given as:

$\sigma_{\mathrm{JC}}=\left(A+B \varepsilon^{n}\right)\left(1+C \ln \frac{\dot{\varepsilon}}{\dot{\varepsilon_{0}}}\right)\left[1-\left(\frac{T-T_{0}}{T_{\mathrm{m}}-T_{0}}\right)^{m}\right]$

At the interface between the particle and the substrate, friction was considered. A modified Coulomb model was applied (i.e., the limit shear $\tau$ grows linearly with the contact pressure, until an upper value, namely $\tau_{\max }$, is reached). Metallurgical adhesion was not considered as it was not believed to have an important influence on the deformation process during impact. All the material parameters are summarized in Table 2.

In order to achieve numerical convergence under intense deformation conditions usually found in cold spray, an adaptive meshing tool (adaptive Lagrangian-Eulerian or ALE) available in the Abaqus software was applied to a domain which corresponded to the particles and the part of the substrate closer to the particle (i.e., the part finely meshed). ALE performed a regularization of the distorted mesh by displacing the nodes at the interior of the selected domain, which resulted in a reduced overall distortion. The solution was then mapped to the new mesh. The whole simulation was divided into several temporal steps, in order to adjust the remeshing parameters during the simulation as often as needed for the benefit of convergence.

\section{Post-processing Heat Treatment}

It is known that in the CGDS process, the resulting depositions usually contain residual stresses, and suffer brittle 
fracture (Ref 64-66). Performing post-deposition heat treatment can reduce porosity and internal defects and improve mechanical properties (Ref 65 ). These heat treatments can result in recovery, recrystallization, and grain growth in the titanium deposits and were shown to significantly increase the ultimate tensile strength (UTS) and yield strength of deposits (Ref 65). In order to enhance the mechanical properties of the deposited components in this study, heat treatments were performed on selected samples. This was done under vacuum to prevent oxidation for three different heat treatments based on the existing literature; $870{ }^{\circ} \mathrm{C}$ for $36 \mathrm{~h}$ (Ref 67 ), $650{ }^{\circ} \mathrm{C}$ for $8 \mathrm{~h}$ (Ref 68), and $1000{ }^{\circ} \mathrm{C}$ for $3 \mathrm{~h}$ (Ref 69).

\section{Mechanical Testing}

Additional mechanical testing of selected samples was completed after heat treatment to assess the mechanical properties of the fabricated parts. These samples were tested using the standard test method for tension testing of metallic materials (ASTM E8) (Ref 70). The dimensions of the CGDS fabricated tensile samples are shown in Fig. 2.

Table 2 Material parameters used for model[taken from (Ref 51, 63)]

\begin{tabular}{lll}
\hline Symbol & \multicolumn{1}{c}{ Description } & Value \\
\hline$P$ & Density $\left(\mathrm{g} \mathrm{cm}^{-3}\right)$ & 8.96 \\
$\mu$ & Shear $(\mathrm{GPa})$ & 41,400 \\
$A$ & $\mathrm{JC}(\mathrm{MPa})$ & 90 \\
$B$ & $\mathrm{JC}(\mathrm{MPa})$ & 292 \\
$C$ & $\mathrm{JC}$ & 0.025 \\
$N$ & $\mathrm{JC}$ & 0.31 \\
$M$ & $\mathrm{JC}$ & 1.09 \\
$\varepsilon_{0}$ & $\mathrm{JC}$ & 1 \\
$c_{0}$ & EOS $\left(\mathrm{m} \mathrm{s}^{-1}\right)$ & 3972 \\
$S$ & EOS & 1.478 \\
$\Gamma_{0}$ & EOS & 2 \\
$T_{\mathrm{m}}$ & Melting point $(\mathrm{K})$ & 1356 \\
$c_{\mathrm{v}}$ & Heat capacity $\left(\mathrm{J} \mathrm{K}^{-1} \mathrm{~kg}^{-1}\right)$ & 383 \\
$K$ & Thermal conductivity & 400 \\
& $\left(\right.$ W K ${ }^{-1}$ ) & \\
\hline
\end{tabular}

JC Johnson-Cooks, EOS equation of state

\section{Results and Discussion}

\section{Deposition Behavior and Sample Characterization}

A mapping of the average particle velocities is shown in Fig. 3. This figure shows that as gas pressure and temperature are increased, the average particle velocities also increase. This is what is expected from the literature (Ref 71). What is notable is that all of these velocities are well below the required critical velocity (indicated by a dotted line in Fig. 3) proposed for titanium proposed by Schmidt et al. (Ref 13), which had been confirmed by others in the literature (Ref 40, 45, 72). The low velocities observed in the current work are attributed to the use of nitrogen gas at lower pressures and temperatures than typically used by others. The lower dotted light in Fig. 3 shows the point at which deposition occurred in this study. It appears that critical velocity for this powder is much lower (almost $50 \%$ ) of that required for the spherical titanium studied by others.

DE was measured by weighing the samples before and after deposition and comparing the mass gain with the mass of powder fed. The powder feed rate was measured directly at the powder feeder exit in testing separate from the operation of the CGDS system. The DE as a function of stagnation temperature for different pressures is shown in Fig. 4. Since the particle velocities were substantially lower than the critical velocities found in the literature, it was expected that DE should also be low. However, the DE was found to reach approximately $90 \%$ for the highest particle velocities. Although high DE is expected with titanium, normally much higher velocities than those obtained in this work are required to approach $100 \% \mathrm{DE}$ (Ref 40, 45, 72).

The density of the deposits as a function of spray process parameters (gas pressure and temperature) is shown in Fig. 5. This figure shows that for all but the lowest parameters, the coatings have high-density levels. It should be noted that these values are averages of the entire cross section of the as-sprayed component, with the majority of the porosity contained in the edges of the deposition, which is a typical characteristic of CGDS titanium (Ref 45, 73).

The results of high DE and low porosity levels suggest that the values reported in the literature for titanium critical
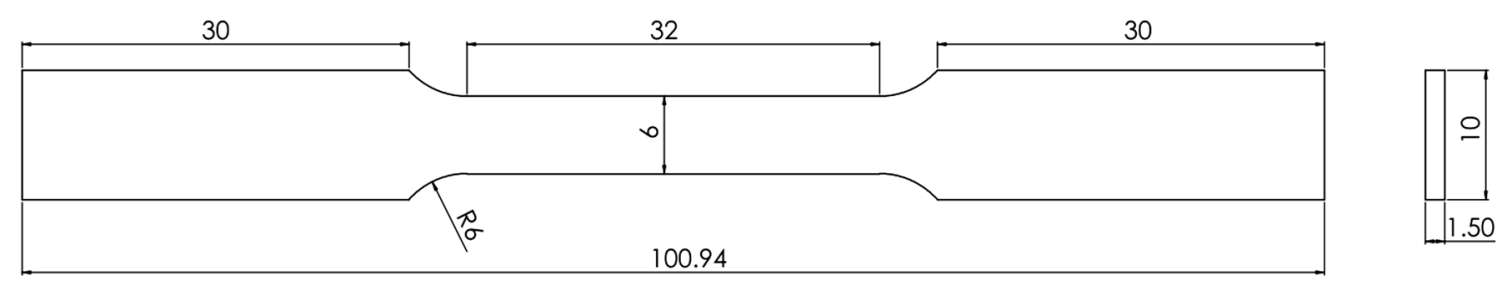

Fig. 2 Dimensions of tensile test specimens (in mm) 


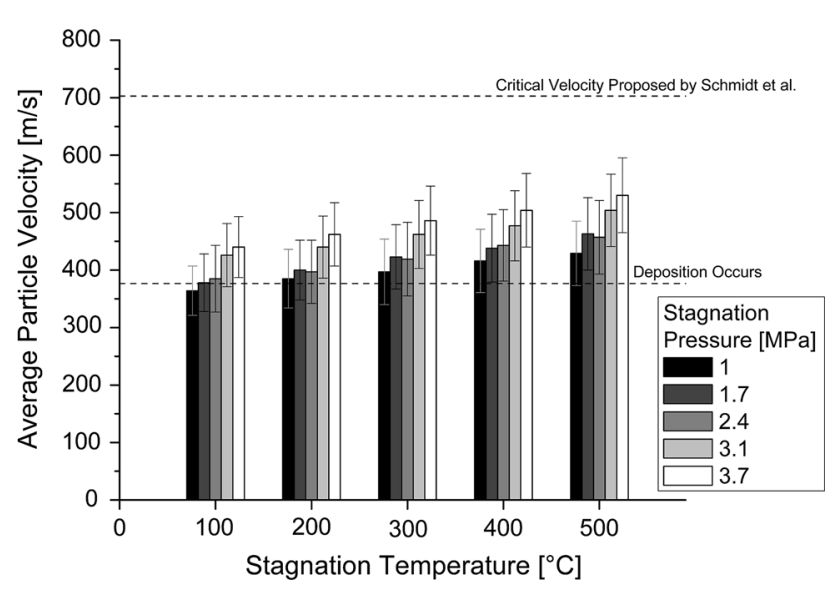

Fig. 3 Average particle velocity for different temperatures and pressures

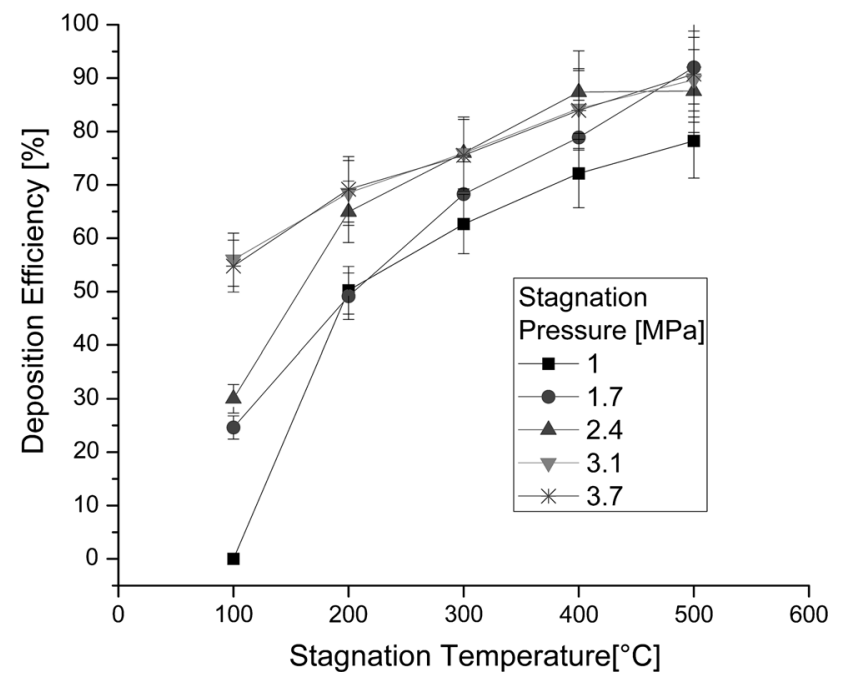

Fig. 4 Deposition efficiency vs gas stagnation temperature for different gas stagnation pressures

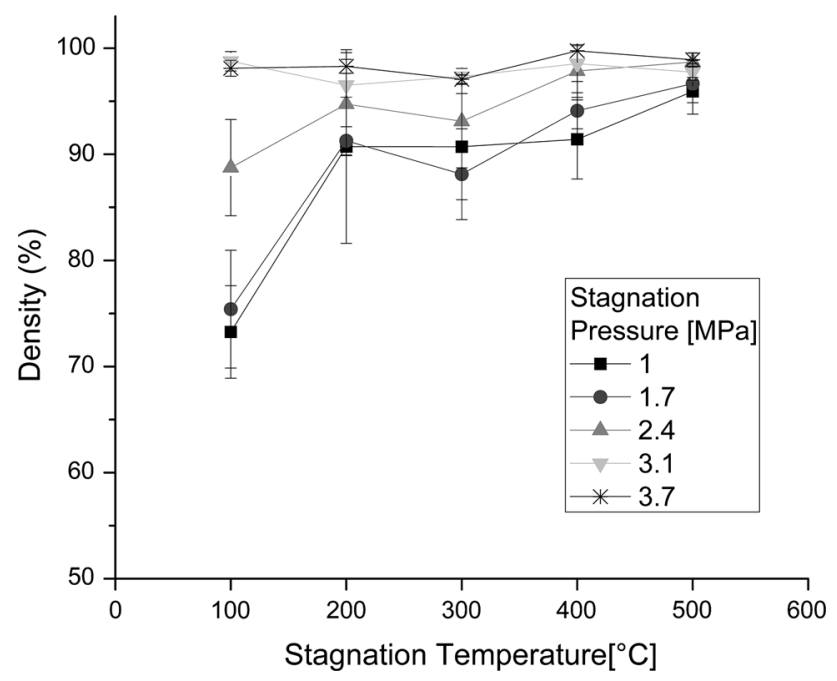

Fig. 5 Coating density vs gas stagnation temperature for different gas stagnation pressures velocity may not be appropriate for non-traditional powder morphology such as the one used in this work. An example of a dense cross section is shown in Fig. 6(a). This result is unexpected since the particle velocities are well below the velocities required for dense coatings according to the literature. According to Wong et al. (Ref 40), a deposition of spherical particles at over $600 \mathrm{~m} / \mathrm{s}$ resulted in a coating of approximately $20 \%$ porosity and $46 \%$ DE. In comparison, the highest velocity average reached in this study was $530 \mathrm{~m} / \mathrm{s}$, which reached a DE of $90 \%$ and porosity of $1.1 \%$. It is clear from this result that the powder morphology is a critical component of the CGDS process. This densification behavior appears to be similar to high green density that was observed in PM processes using this powder (Ref 48).

Although the coatings were dense, the microhardness only ranged from $55.5 \pm 16.0$ to $87.2 \pm 8.2 \mathrm{HV}_{300 \mathrm{~g}}$. These values are substantially lower than expected values for bulk commercially pure titanium [145 HV (Ref 1)] and titanium coatings produced through CGDS [ $>190 \mathrm{HV}$ (Ref 40)]. These results are unforeseen, as in CGDS traditionally dense coatings have a high level of deformation and therefore a high level of cold working which results in higher hardness. The image of the hardness test of assprayed component shown in Fig. 6(b) provides some insight into the deposition behavior of this powder. Cracks can be seen propagating from the indentation. These cracks are suspected to be following particle boundaries, demonstrating that there is very little cohesion between particles. This again is unexpected, since in CGDS the particle velocities required to get a dense coating usually results in strong particle to particle cohesion.

Fracture surfaces of the as-deposited component were investigated with SEM and are shown in Fig. 7. The fractographic analysis leads to no signs of the normal fracture mechanisms seen in titanium. The lack of characteristic markings, such as cup and cone dimple rupture, leads to the conclusion that this fracture surface contains little to no metallurgical bonding (Ref 74). These types of fracture surfaces are much closer to those seen in PM at a green state (before sintering) (Ref 75).

\section{Understanding Deposition Through Single Impact Analysis and Modeling of Particle Impacts}

In order to enhance the understanding of the deposition behavior of the particles during impact, modeling and single impact testing was done for a single set of deposition parameters. The CGDS spray parameters used to for this model and single impact analysis were $1.7 \mathrm{MPa}$ and $500{ }^{\circ} \mathrm{C}$. These parameters were selected as the DE and density did not appear to increase substantially beyond this point. These CGDS spray parameters resulted in an average particle velocity of $463 \mathrm{~m} / \mathrm{s}$. The substrate temperature was 


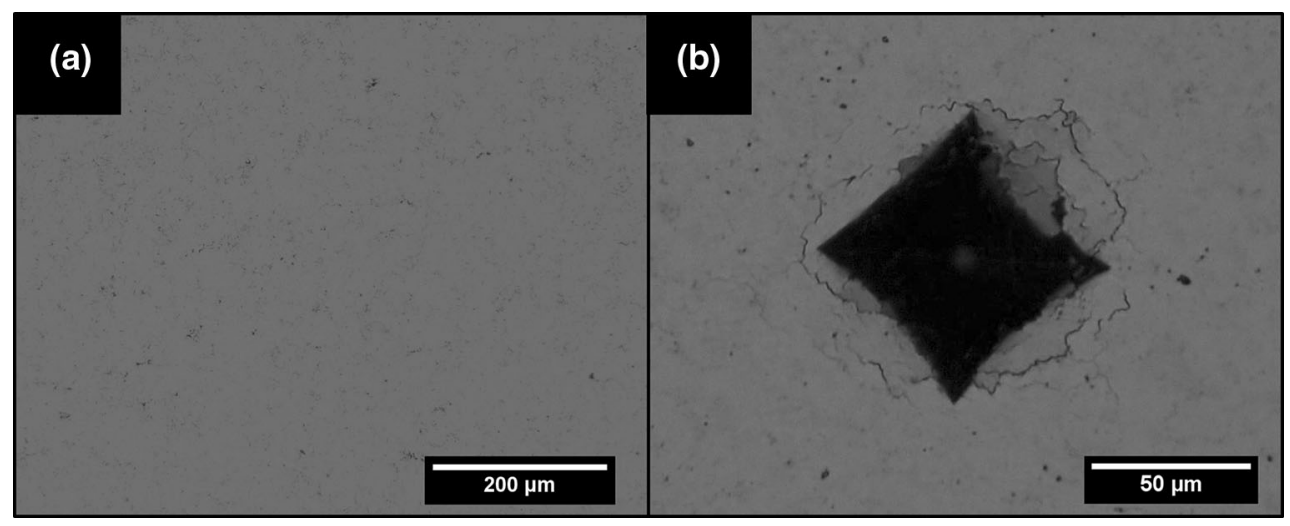

Fig. 6 Optical image showing a near fully dense deposition (a) with cracking around Vickers microhardness indentation (b) (deposited at gas pressure and temperature of $1.7 \mathrm{MPa}$ and $500{ }^{\circ} \mathrm{C}$ )

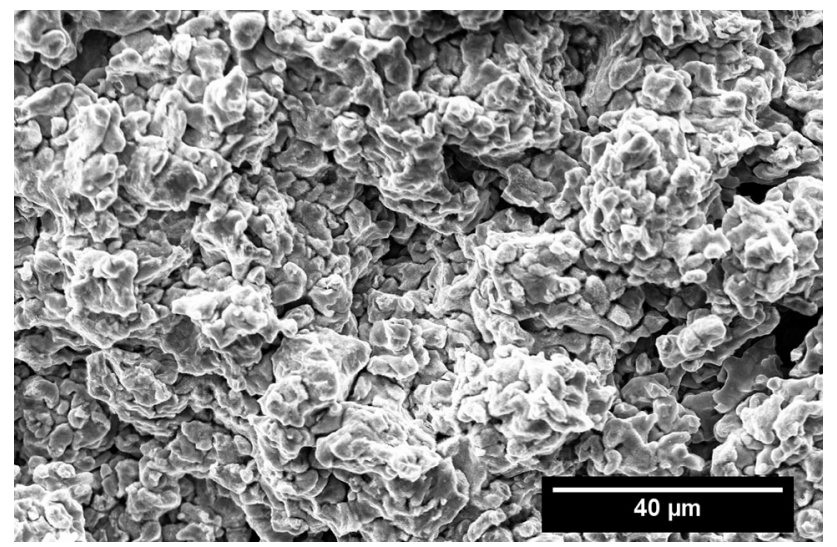

Fig. 7 SEM image of fracture surface of CGDS-deposited titanium powder

found to be $188^{\circ} \mathrm{C}$. This particle velocity and substrate temperature were used as inputs for the model. The particle temperature could not be measured and was assumed to be the same temperature as the substrate at the point of impact.

It is hypothesized that during impact, the unique particle morphology allows the particles to anchor to one another while collapsing and flattening on themselves, resulting in a high DE and dense structure with very little cohesion between the particles. The results of the simulations showing the impact behavior of two particles with real geometries is shown in Fig. 8(a), (b), and (c). This figure acts as a visual aid, showing how, as a result of powder morphology, the particle is able to collapse almost fully during impact. Figure 8(d), (e), and (f), shows SEM images of particles that have not been compacted during impact with the substrate. It is clear from these images that the model accurately predicted the behavior of the coral-shaped particles.

Figure 8 not only shows the method for densification, but sheds light on the how the particles would be able to interlock with each other without creating metallic bonds between the particles. This interlocking of the particles helps explain why such high DE is achievable at low particle velocities. Spherical particles, which are normally used in CGDS, would require adiabatic sheer instability at the impact zone to achieve bonding and form a coating. In this case, this is no longer required for this morphology of powder.

Figure 9 shows the resulting plastic equivalent strain (PEEQ) contours of spherical titanium particles and coralshaped particles upon impact with the substrate obtained from the model. The spherical particles (Fig. 9a) only have PEEQ in the immediate vicinity of the impact zone. These particles also show no metal jet formation along impact area. This result shows that these spherical particles are unlikely to adhere at these low impact velocities. Figure 9(b) shows areas of much higher peek throughout the particles, but especially at the impact area. This higher PEEQ may be a result of decreased interfacial contact area, which could result in bonding but only on a small fraction of the interface. Zones of deformation can also be seen away from the impact zones of the particles, especially concentrated at thin zones of the particle. This localized plastic deformation results from a torque caused by inertia force of a portion of the particle created during impact. This deformation is responsible for the collapse of the particle and is assumed to be the cause of the resulting easy densification.

It can also been extrapolated that the impact of subsequent particles is responsible for the densification of the remainder of the porosity that is left at the top of the particle. Overall, this deformation results in a much higher flattening ratio for the coral-shaped powder. The flattening ratio, defined by the ratio of the longest length of the particle to the shortest length of the particle, of the center particle in the circular simulation increased by $24 \%$, while the flattening ratio of the center particle in the coral-shaped powder increased by $64 \%$. 


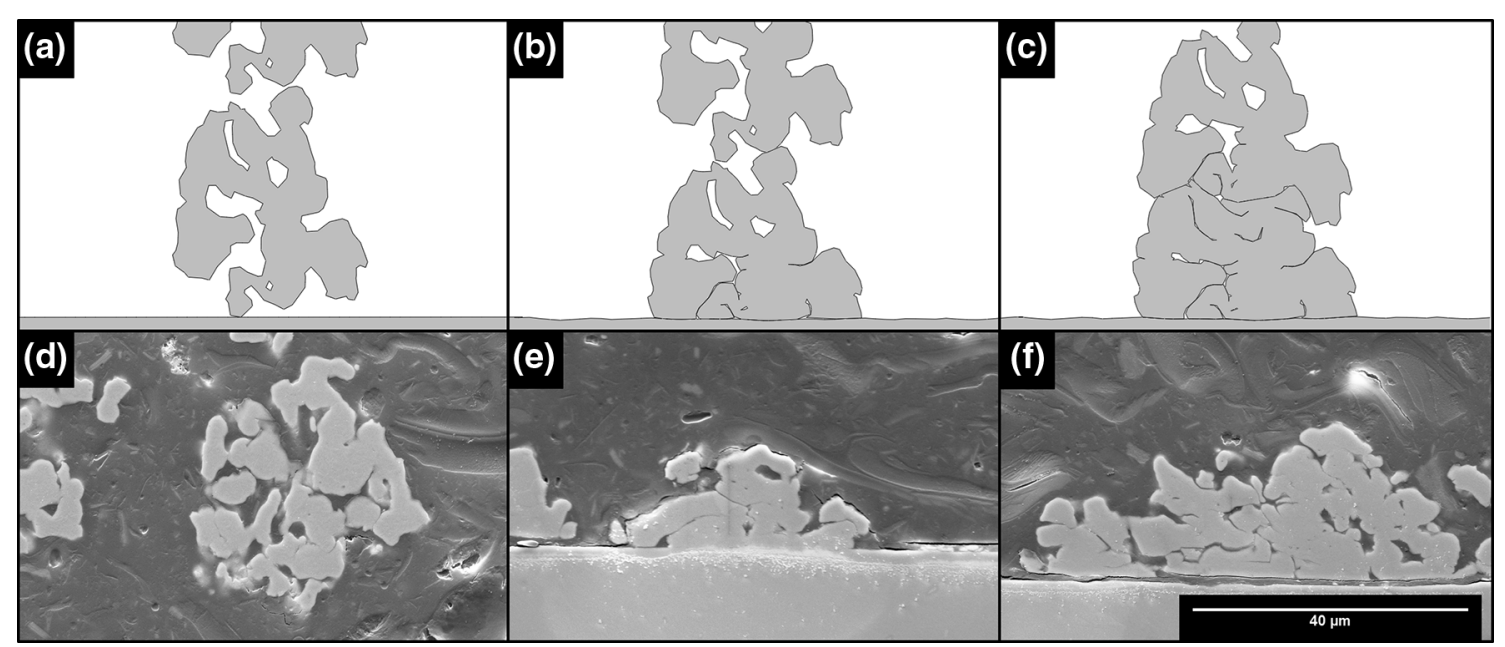

Fig. 8 Modeling and SEM images of densification behavior of coral-like powder showing a particle without impact (a, d), single particle after impact with substrate (b,e), and a multiple particle impact (c, f)

Fig. 9 PEEQ contours of five spherical (a) and five coralshaped particles (b) before impact (left) and after impact with a velocity of $463 \mathrm{~m} / \mathrm{s}$ and a temperature of $188^{\circ} \mathrm{C}$ (right)

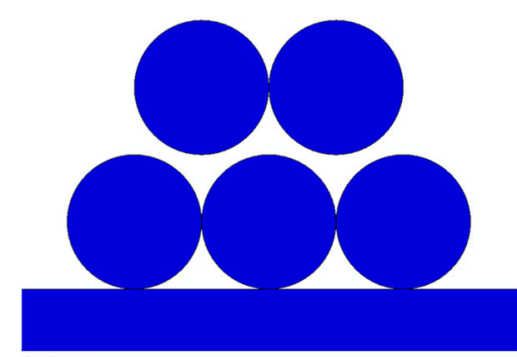

(a)

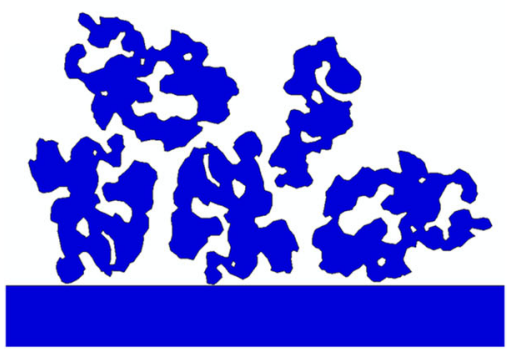

(b)
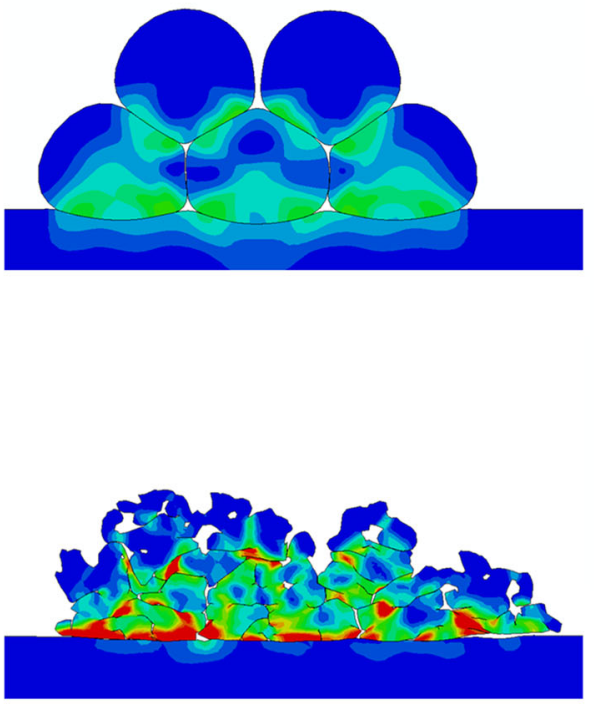

PEEQ

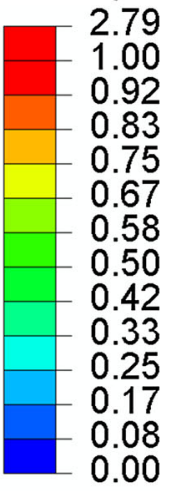

2.79

1.00

0.83

0.75

0.67

0.58

0.25

0.17

0.00
Based on these modeling results, it is sensible to conclude that with the coral-shaped particles, metallurgical adhesion could happen more readily than for the case with spherical particles, with the same impact velocities, due to high localized PEEQ at the impact zones. However, this contact area would be quite small. It was also observed that there was mechanical interlocking between particles. Both of these bonding mechanisms would result in a week bond, but be favorable to a high $\mathrm{DE}$. The modeling results also demonstrate how this powder is able to reach such high density, even at such low particle velocities through plastic deformation throughout the entire particle, resulting in a high flattening ratio.

\section{Heat Treatment and Resulting Properties}

The CGDS parameters used to fabricate the components to be heat-treated are $1.7 \mathrm{MPa}$ and $500{ }^{\circ} \mathrm{C}$. Since the behavior of the deposits appears to be similar to that of green compacts in PM, the low hardness and poor cohesion of the fabricated components can potentially be overcome by growing metallic bonds between particles through heat treatment (Ref 76). These heat treatments were done under vacuum $\left(1 \times 10^{-7}\right.$ Torr $)$ for the specified times and temperatures listed in "Post-processing Heat Treatment" section. SEM images of these samples after hardness testing, followed by etching (solution of 


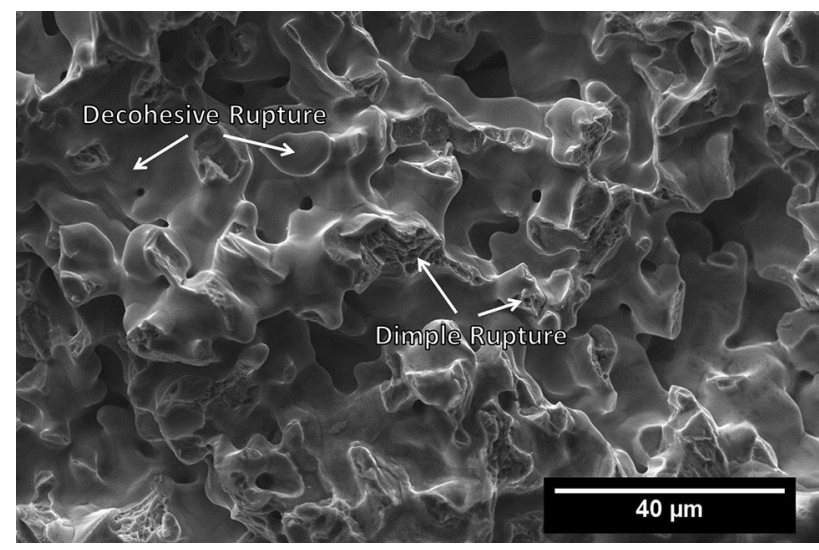

Fig. 10 SEM image of fracture surface of heat-treated tensile specimen

1:1:20 of $\mathrm{HF}: \mathrm{H}_{2} \mathrm{O}_{2}$ :deionized water), are shown in Fig. 10, and hardness results are shown in Table 3.

In Fig. 11(a), cracking and delamination between particle boundaries can be seen around the edges of the microhardness indent. Since this sample does not have a heat treatment, it is expected to have the same cracking artifacts seen earlier as well as having a low hardness (Table 3). Figure 11(b) and (d) shows that this cracking around the indents is no longer present. This result shows that cracks can no longer propagate through the particle boundaries, indicating that metallic bonding has occurred between the particles. For the heat treatment $\mathrm{C}$, an increase in hardness is present indicating that the cohesion between the particles has increased; however, cracking at the particle boundaries is still visible indicating that the heat treatment process was not adequate to induce full bonding between the particles (Fig. 11(c)).

It was found that for two of the heat treatments (B and D), the component microhardness was above that for bulk materials. This additional hardness is likely due to increased oxygen content present in the finished component (Ref 1). This small percentage of oxygen was likely present in the original powder as the CGDS process is done in an inert nitrogen environment and the heat treatment occurred in a vacuum $\left(<10^{-7}\right.$ Torr $)$

Tensile samples (dimensions found in Fig. 2) were fabricated using CGDS using the using the same spray parameters as the previous heat treatment testing (1.7 MPa and $500{ }^{\circ} \mathrm{C}$ nitrogen). The samples were then separated from the substrate. These samples were heat-treated at $1000{ }^{\circ} \mathrm{C}$ for $3 \mathrm{~h}$, as this heat treatment resulted in the highest hardness in the heat treatment testing. After heat treatment, the samples have been machined to final dimensions. Stress relief annealing at $550{ }^{\circ} \mathrm{C}$ for $2 \mathrm{~h}$ (Ref 1) was done after machining.

Tensile testing of the samples resulted in an UTS of $277 \pm 88 \mathrm{MPa}$. The average value found is above the minimum value listed for UTS in the literature of $240 \mathrm{MPa}$ (Ref 1). However, all three samples underwent brittle fracture will little plastic deformation.

Figure 11(d) shows that the component recrystallized and that the particles were bonded during the heat treatment. Therefore, it would be expected that any residual stress or cold work would be eliminated, and the component should have failed in a similar ductile manner as the bulk material. However, post-fracture analysis showed that the fracture propagated from flaws created during final machining steps at the neck area of the sample. These flaws would have created stress concentrations during tensile testing, resulting crack propagation and sudden, brittle fracture. Therefore, the values for the UTS do not reflect the true strength of the material, but a minimum value for components without stress concentrations.

Fractographic examination of the fracture surfaces using SEM shows a very unique topography. The majority of the fracture area was found to be a smooth surface of irregular shapes without normal fracture patterns such as dimple rupture, cleavage, or fatigue markings. This kind of fracture is referred to as decohesive rupture, which normally exhibits little to no bulk plastic deformation. This type of fracture can occur as a result of a unique microstructure and it is associated with rupture along grain boundaries (Ref 74). In this case, a fracture surface that appears to follow the original particle boundaries is seen. This kind of surface is seen commonly in PM fracture surfaces after sintering (Ref 76).

This fracture surface also shows areas of dimple rupture, showing a failure by a process known as microvoid coalescence (Ref 74). This type of fracture exhibits numerous cuplike depressions, referred to as dimples. This type of mixed fracture mode surface is a result of an inappropriate heat treatment/ sintering, as there is preferential failure along particle boundaries. Continued sintering should
Table 3 Vickers hardness values before and after heat treatment

\begin{tabular}{lccc}
\hline Designation letter & Temperature $\left({ }^{\circ} \mathrm{C}\right)$ & Time $(\mathrm{h})$ & Hardness $\left(\mathrm{HV}_{300 \mathrm{~g}}\right)$ \\
\hline A & N/A & N/A & $80 \pm 12$ \\
B & 870 & 36 & $214 \pm 36$ \\
C & 650 & 8 & $164 \pm 43$ \\
D & 1000 & 3 & $214 \pm 43$ \\
\hline
\end{tabular}




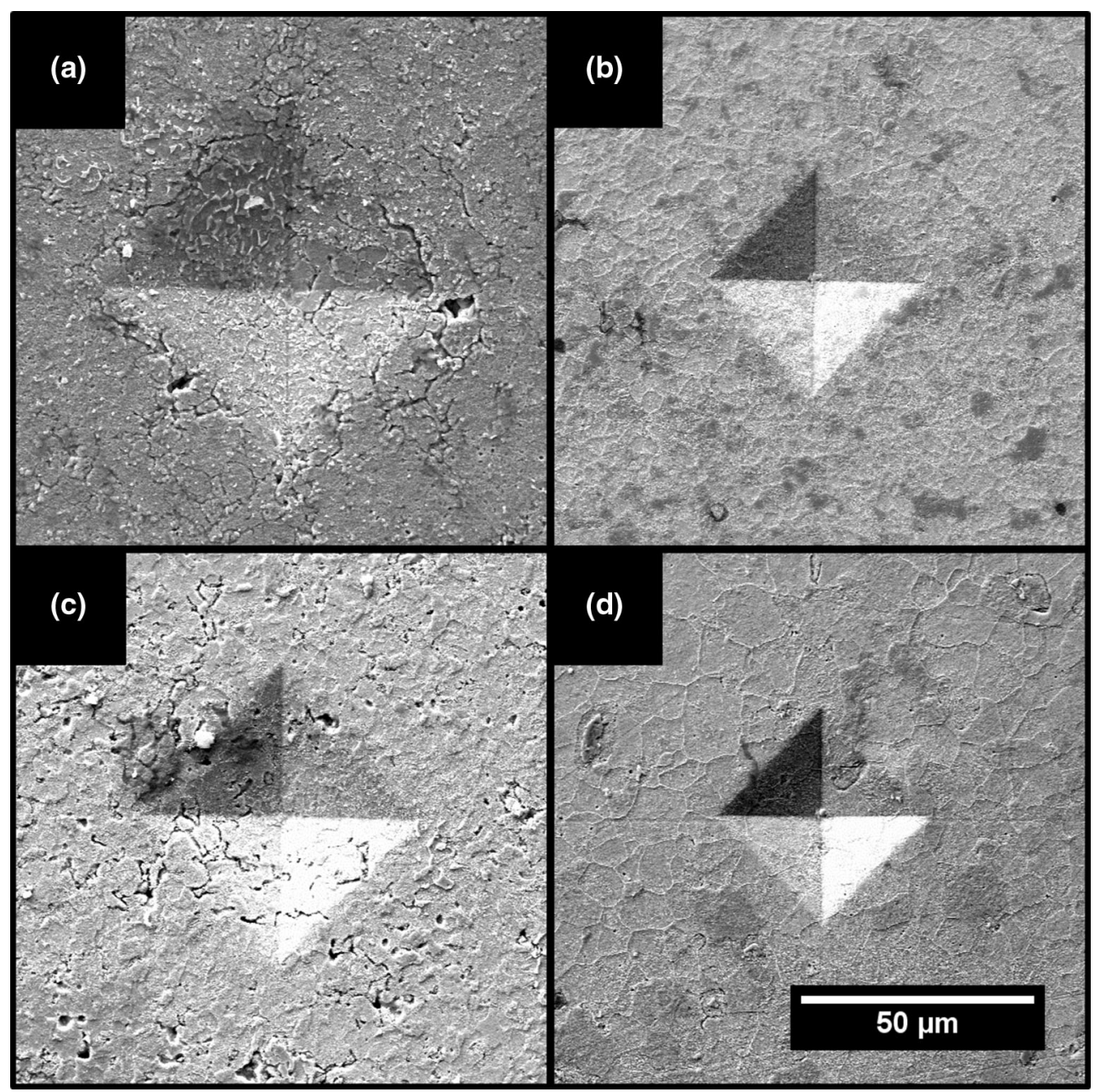

Fig. 11 SEM images of etched samples (a) before heat treatment, (b) after $870{ }^{\circ} \mathrm{C}$ for $36 \mathrm{~h}$, (c) $650{ }^{\circ} \mathrm{C}$ for $8 \mathrm{~h}$, and (d) $1000{ }^{\circ} \mathrm{C}$ for $3 \mathrm{~h}$

increase the number and area fraction of the ductile torn regions ( $\operatorname{Ref} 3,76)$.

\section{Conclusion}

Fully dense titanium parts were fabricated using CGDS as an AM process. This was accomplished using low-pressure and low-temperature nitrogen as the process gas. The key to this result is attributed to the unique coral-shaped powder morphology that allows the easy densification and deposition through CGDS. Although the properties of these components are not ideal in the as-manufactured state, a short heat treatment of $3 \mathrm{~h}$ results in properties comparable to bulk material in terms of hardness and UTS.

This is a promising approach for CGDS as a method for AM of titanium parts. The low powder cost and the advantages of additive manufacturing could allow for a substantial cost savings in titanium part production when compared to traditional manufacturing methods. CGDS also makes AM of large titanium parts attractive as it addresses some of the drawbacks of the other AM processes such as deposition rates, post-processing and shrinkage, and size limitations. Lastly, the CGDS process cost is kept low due to the ability to use nitrogen and low process parameters-which would not be possible using traditional spherical powders.

With these cost saving advantages, AM of titanium using Armstrong process powder and CGDS could lead to a paradigm shift of titanium production, allowing titanium to enter markets that under traditional methods would be far too expensive.

Acknowledgments The authors of this paper would like to gratefully acknowledge the contributions of Damien Mangabhai and René Cooper of Cristal Metals. 


\section{References}

1. M.J. Donachie, Titanium: A Technical Guide, 2nd ed., ASM International, Materials Park, OH, 2000

2. J. Capus, Conventional PM Still a Challenge for Titanium and Alloys, Met. Powder Rep., 2014, 69(6), p 18-20. doi:10.1016/ S0026-0657(14)70274-7

3. I. Gibson, D. Rosen, and B. Strucker, Additive Manufacturing Technologies, 2nd ed., Springer, New York, 2015

4. N. Guo and M.C. Leu, Additive Manufacturing: Technology, Applications and Research Needs, Front. Mech. Eng., 2013, 8(3), p 215-243

5. W.E. Frazier, Metal Additive Manufacturing: A Review, $J$. Mater. Eng. Perform., 2014, 23, p 1917-1928

6. Fraunhofer Institute for Manufacturing Technology and Advanced Materials, Additive Manufacturing: Electron Beam Melting (Fraunhofer Institute for Manufacturing Technology and Advanced Materials IFAM, Dresden, Germany, 2012)

7. J. Hiemenz, Electron Beam Melting, Adv. Mater. Process., 2007, 165(3), p 45-46

8. X. Gong, T. Anderson, and K. Chou, Review on Powder-Based Electron Beam Additive Manufacturing Technology, Proceedings of the ASME/ISCIE 2012 International Symposium on Flexible Automation, St. Louis, MO, USA, 2012

9. T. Wang, Y.Y. Zhu, S.Q. Zhang, H.B. Tang, and H.M. Wang, Grain Morphology Evolution Behavior of Titanium Alloy Components During Laser Melting Deposition Additive Manufacturing, J. Alloys Compd., 2015, 632, p 505-513. doi:10.1016/j. jallcom.2015.01.256

10. E. Uhlmann, R. Kersting, T.B. Klein, M.F. Cruz, and A.V. Borille, Additive Manufacturing of Titanium Alloy for Aircraft Components, Procedia CIRP, 2015, 35, p 55-60. doi:10.1016/j. procir.2015.08.061

11. J.R. Davis (ed.), in Handbook of Thermal Spray Technology (ASM International, Materials Park, USA, 2004)

12. M. Grujicic, C. Zhao, W. DeRosset, and D. Helfritch, Adiabatic Shear Instability Based Mechanism for Particles/substrate Bonding in the Cold-Gas Dynamic-Spray Process, Mater. Des., 2004, 25(8), p 681-688. doi:10.1016/j.matdes.2004.03.008

13. T. Schmidt, F. Gärtner, H. Assadi, and H. Kreye, Development of a Generalized Parameter Window for Cold Spray Deposition, Acta Mater., 2006, 54(3), p 729-742. doi:10.1016/j.actamat.2005. 10.005

14. H. Assadi, F. Gärtner, T. Stoltenhoff, and H. Kreye, Bonding Mechanism in Cold Gas Spraying, Acta Mater., 2003, 51(15), p 4379-4394. doi:10.1016/S1359-6454(03)00274-X

15. J. Wu, H. Fang, S. Yoon, H. Kim, and C. Lee, The Rebound Phenomenon in Kinetic Spraying Deposition, Scr. Mater., 2006, 54(4), p 665-669. doi:10.1016/j.scriptamat.2005.10.028

16. T. Hussain, D.G. McCartney, P.H. Shipway, and D. Zhang, Bonding Mechanisms in Cold Spraying: The Contributions of Metallurgical and Mechanical Components, J. Therm. Spray Technol., 2009, 18(3), p 364-379. doi:10.1007/s11666-009-9298-1

17. T. Schmidt, F. Gaertner, and H. Kreye, New Developments in Cold Spray Based on Higher Gas and Particle Temperatures, $J$. Therm. Spray Technol., 2006, 15, p 488-494

18. T. Han, Z. Zhao, B.A. Gillispie, and J.R. Smith, Effects of Spray Conditions on Coating Formation by the Kinetic Spray Process, $J$. Therm. Spray Technol., 2005, 14(3), p 373-383. doi:10.1361/ $105996305 \times 59369$

19. E. Sansoucy, B. Jodoin, P. Richer, and L. Ajdelsztajn, Effect of Spraying Parameters on the Microstructureand Bond Strength of Cold Spray Aluminum Alloy Coatings, Proceedings of the 2006 International Thermal Spray Conference (ASM International, Seattle, Washington, DC, USA, 2006)
20. D. Wright, Advancing Cold Spray Applications to Industry Markets, AeroMat 2011, Long Beach, CA, USA, 2011

21. J. Villafuerte, Ed., Modern Cold Spray, Springer, Windsor, ON, Canada, 2015, doi:10.1007/978-3-319-16772-5

22. D. Gasme, Verfahren Zum Herstellen Eines Kochgeschirrs Für Einen Induktionsherd (A Method of Manufacturing a Cooking Vessel for Induction Cooker), Germany, European Patent 1599 116 B1, 2008

23. P.A. Kramer, Spray Processing of Pourus Medical Devices, US Patent 7163715 B1, 2007

24. V.K. Champagne, The Repair of Magnesium Rotorcraft Components by Cold Spray, J. Fail. Anal. Prev., 2008, 2008(8), p 164175

25. D. MacDonald and B. Jodoin, Study on the Restoration of Aluminum Aerospace IVD Coatings Using Cold Gas Dynamic Spray," Thermal Spray 2013-Innovative Coating Solutions for the Global Economy. Proceedings of the International Thermal Spray Conference, R.S. Lima, A. Agarwal, M.M. Hyland, Y.C. Lau, G. Mauer, A. McDonald, and F.L. Toma, Eds., ASM International, Busan, Republic of Korea, 2013, p 161-165

26. C. Widener, R. Hrabe, B. James, and V. Champagne, B1 BomberFEB Panel Repair by Cold Spray, Cold Spray Action Teem Meeting, Worcester, MA, USA, 2013

27. M. Yandouzi, S. Gaydos, D. Guo, R. Ghelichi, and B. Jodoin, Aircraft Skin Restoration and Evaluation, J. Therm. Spray Technol., 2014, 23, p 1281-1290. doi:10.1007/s11666-014-0130-1

28. Y. Cormier, P. Dupuis, B. Jodoin, and A. Corbeil, Mechanical Properties of Cold Gas Dynamic-Sprayed Near-Net-Shaped Fin Arrays, J. Therm. Spray Technol., 2014, 24, p 476-488. doi:10. 1007/s11666-014-0203-1

29. A. Sova, S. Grigoriev, A. Okunkova, and I. Smurov, Potential of Cold Gas Dynamic Spray as Additive Manufacturing Technology, Int. J. Adv. Manuf. Technol., 2013, 2013(69), p 2269-2278. doi: $10.1007 / \mathrm{s} 00170-013-5166-8$

30. Y. Cormier, P. Dupuis, B. Jodoin, and A. Corbeil, Net Shape Fins for Compact Heat Exchanger Produced by Cold Spray, J. Therm. Spray Technol., 2013, 22, p 1210-1221

31. P. Dupuis, Y. Cormier, A. Farjam, B. Jodoin, and A. Corbeil, Performance Evaluation of Near-Net Pyramidal Shaped Fin Arrays Manufactured by Cold Spray, Int. J. Heat Mass Transf., 2014, 2014(69), p 34-43. doi:10.1016/j.ijheatmasstransfer.2013. 09.072

32. K. Slattery and M. Charles, St., Sprayed Preforms for Forming Structural Members, J. Chem. Inf. Model., 1989, 53(19), p 160

33. J. Pattison, S. Celotto, R. Morgan, M. Bray, and W. O'Neill, Cold Gas Dynamic Manufacturing: A Non-Thermal Approach to Freeform Fabrication, Int. J. Mach. Tools Manuf., 2007, 47(3-4), p 627-634. doi:10.1016/j.ijmachtools.2006.05.001

34. P. Heinrich, P. Richter, H. Holl, and E. Bahr, Method for Producing a Pipe, US Patent 2012/0273152 A1, 2012

35. E. Calla, S. Pabla, and R. Goetze, Turbine Rotor Fabrication Using Cold Spraying, USA, US Patent 8261444 B2, 2010

36. M.Z. Jahedi, S.H. Zahiri, S. Gulizia, B. Tiganis, C. Tang, and D. Fraser, Direct Manufacturing of Titanium Parts by Cold Spray, Mater. Sci. Forum, 2009, 618-619, p 505-508. doi:10.4028/www. scientific.net/MSF.618-619.505

37. Plasma Giken Co., The Next Generaion in Cold Spray Technology: Introducing Cold Spray PCS-1000 and PCS-800 (Plasma Giken Co., 2016)

38. P. Calefati, Borealis: Enlightening Next Generation of Material, Factories of the Future: Manufacturing Processes for Complex Structures and Geometries with Efficient Use of Material, FoF 2014-2 (Prima Industrie SpA, 2014)

39. D. Goldbaum, J.M. Shockley, R.R. Chromik, A. Rezaeian, S. Yue, J.G. Legoux, and E. Irissou, The Effect of Deposition 
Conditions on Adhesion Strength of Ti and Ti6Al4V Cold Spray Splats, J. Therm. Spray Technol., 2012, 21(2), p 288-303

40. W. Wong, E. Irissou, A.N. Ryabinin, J.G. Legoux, and S. Yue, Influence of Helium and Nitrogen Gases on the Properties of Cold Gas Dynamic Sprayed Pure Titanium Coatings, J. Therm. Spray Technol., 2011, 20(1-2), p 213-226

41. S. Gulizia, C. Aus, A. Trentin, S. Vezzù, S. Rech, I. Marghera, P. King, M. Jahedi, M. Guagliano, and I. Milano, Characterisation of Cold Spray Titanium Coatings, Mater. Sci. Forum, 2010, 656, p 898-901

42. S.H. Zahiri, C.I. Antonio, and M. Jahedi, Elimination of Porosity in Directly Fabricated Titanium via Cold Gas Dynamic Spraying, J. Mater. Process. Technol., 2009, 209(2), p 922-929

43. S. Gullzia, B. Tiganis, M.Z. Jahedi, N. Wright, T. Gengenbach, and C. MacRae, Effects of Cold Spray Process Gas Temperature on CP Titanium Structure, Proc. Int. Therm. Spray Conf., 2009, p 237-242. doi:10.1361/cp2009itsc0237

44. W. Wong, A. Rezaeian, E. Irissou, J.G. Legoux, and S. Yue, Cold Spray Characteristics of Commercially Pure Ti and Ti-6Al-4V, Adv. Mater. Res., 2010, 89-91, p 639-644

45. W. Wong, P. Vo, E. Irissou, A.N. Ryabinin, J.G. Legoux, and S. Yue, Effect of Particle Morphology and Size Distribution on Cold-Sprayed Pure Titanium Coatings, J. Therm. Spray Technol., 2013, 22(7), p 1140-1153

46. K. Araci, D. Mangabhai, and K. Akhtar, Production of Titanium by the Armstrong Process ${ }^{\circledR}$, Titanium Powder Metall., 2015, p 149-162. doi:10.1016/B978-0-12-800054-0.00009-5

47. D.R. Armstrong, S.S. Borys, and R.P. Anderson, Method of Making Metals and Other Elements from the Halid Vapor of the Metal, USA, US Patent 5958106, 1999

48. W.H.P. Bill, C.A. Blue, J.O. Kiggans, and J.D.K. Rivard, Powder Metallurgy and Solid State Processing of Armstrong Titanium and Titanium Alloy Powders, ITA Annual Conference 2007 (Orlando, USA, 2007)

49. W.H. Peter, Solid State Processing of New Low Cost Titanium Powders Enabling Affordable Automotive Components. 13th Diesel Engine-efficiency and Emissions Research Conference (DEER), Detroit, MI, USA, 2007. papers3://publication/uuid/ 1C6871C2-307C-4957-83F8-7A1E1F829132

50. S. Yin, P. He, H. Liao, and X. Wang, Deposition Features of Ti Coating Using Irregular Powders in Cold Spray, J. Therm. Spray Technol., 2014, 23, p 984-990. doi:10.1007/s11666-014-0116-z

51. G. Bae, Y. Xiong, S. Kumar, K. Kang, and C. Lee, General Aspects of Interface Bonding in Kinetic Sprayed Coatings, Acta Mater., 2008, 56(17), p 4858-4868

52. S. Rahmati and A. Ghaei, The Use of Particle/substrate Material Models in Simulation of Cold-Gas Dynamic-Spray Process, $J$. Therm. Spray Technol., 2014, 23(3), p 530-540

53. K. Yokoyama, M. Watanabe, S. Kuroda, Y. Gotoh, T. Schmidt, and F. Gärtner, Simulation of Solid Particle Impact Behavior for Spray Processes, Mater. Trans., 2006, 47(7), p 1697-1702

54. W.-Y. Li, H. Liao, C.-J. Li, G. Li, C. Coddet, and X. Wang, On High Velocity Impact of Micro-Sized Metallic Particles in Cold Spraying, Appl. Surf. Sci., 2006, 253(5), p 2852-2862. doi:10. 1016/j.apsusc.2006.05.126

55. X. Wang, F. Feng, M.A. Klecka, M.D. Mordasky, J.K. Garofano, T. El-Wardany, A. Nardi, and V.K. Champagne, Characterization and Modeling of the Bonding Process in Cold Spray Additive Manufacturing, Addit. Manuf., 2015, 8, p 149-162

56. F. Gärtner, C. Borchers, T. Stoltenhoff, H. Kreye, and H. Assadi, Numerical and Microstructural Investigations of the Bonding Mechanisms in Cold Spraying, in Thermal Spray 2003: Advancing the Science and Applying the Technology, ed. by C. Moreau, B. Marple, 2003, p 1-8

57. P.C. King, G. Bae, S.H. Zahiri, M. Jahedi, and C. Lee, An Experimental and Finite Element Study of Cold Spray Copper
Impact onto Two Aluminum Substrates, J. Therm. Spray Technol., 2010, 19(3), p 620-634

58. Y. Cormier, P. Dupuis, B. Jodoin, and A. Ghaei, Finite Element Analysis and Failure Mode Characterization of Pyramidal Fin Arrays Produced by Masked Cold Gas Dynamic Spray, J. Therm. Spray Technol., 2015, 24(8), p 1549-1565. doi:10.1007/s11666015-0317-0

59. R. Ghelichi, S. Bagherifard, M. Guagliano, and M. Verani, Numerical Simulation of Cold Spray Coating, Surf. Coat. Technol., 2011, 205(23-24), p 5294-5301. doi:10.1016/j.surfcoat.2011. 05.038

60. W.-Y. Li and W. Gao, Some Aspects on 3D Numerical Modeling of High Velocity Impact of Particles in Cold Spraying by Explicit Finite Element Analysis, Appl. Surf. Sci., 2009, 255, p 7878-7892

61. T. Antoun, L. Seaman, D.R. Curran, G.I. Kanel, S.V. Razorenov, and A.V. Utkin, Spall Fracture, Springer, New York, 2003

62. G.R. Johnson and W.H. Cook, A Constitutive Model and Data for Metals Subjected to Large Strains, High Strain Rates and High Temperatures, Proceedings of the 7th International Symposium on Ballistics, 1983, p 541-547. doi:10.1038/nrm3209

63. D. Giraud, Study of the Mechanical and Metallurgical Contributions to Coating-Substrate Bonding in Cold Spray for Aluminium/Polyamide 66 and Titanium/Ti-6Al-4V (l'École nationale supérieure des mines de Paris, Paris, France, 2014)

64. A.C. Hall, D.J. Cook, R.A. Neiser, T.J. Roemer, and D.A. Hirschfeld, The Effect of a Simple Annealing Heat Treatment on the Mechanical Properties of Cold-Sprayed Aluminum, J. Therm. Spray Technol., 2006, 15(2), p 233-238. doi:10.1361/ 105996306X108138

65. T. Hussain, Cold Spraying of Titanium: A Review of Bonding Mechanisms, Microstructure and Properties, Key Eng. Mater., 2013, 2012(533), p 53-90. doi:10.4028/www.scientific.net/KEM. 533.53

66. W.-Y. Li, C.-J. Li, and H. Liao, Effect of Annealing Treatment on the Microstructure and Properties of Cold-Sprayed $\mathrm{Cu}$ Coating, $J$. Therm. Spray Technol., 2006, 15(2), p 206-211. doi:10.1361/ 105996306X108066

67. T. Enjo, K. Ikeuchi, N. Akikawa, and T. Maruyama, Effect of a-B Transformation on the Diffusion Welding of Titanium, Trans. JWRI, 1980, 9(1), p 61-67

68. K. Okazaki and H. Conrad, Recrystallization and Grain Growth in Titanium: I. Characterization of the Structure, Metall. Trans., 1972, 3, p 2411-2421

69. M. Pushkareva, J. Adrien, E. Maire, and A. Weck, Three-Dimensional Investigation of Void Growth Leading to Fracture in Commercially Pure Titanium, 1st International Conference on 3D Materials Science, 2012, p 61-66

70. L. Alloy, S. Steel, M. Products, A.U. Tensile, and C.A. Force, Standard Test Methods for Tension Testing of Metallic Materials, Vol 1, 2012, p 1-27

71. R.C. Dykhuizen and M.F. Smith, Gas Dynamic Principles of Cold Spray, J. Therm. Spray Technol., 1998, 7, p 205-212

72. W. Wong, A. Rezaeian, and S. Yue, Effects of Gas Temperature, Gas Pressure, and Particle Characteristics on Cold Sprayed Pure Titanium Coatings, 2009, p 4000

73. C.-J. Li and W.-Y. Li, Deposition Characteristics of Titanium Coating in Cold Spraying, Surf. Coat. Technol., 2003, 167(2-3), p 278-283. doi:10.1016/S0257-8972(02)00919-2

74. ASM International, Fractography, in ASM Metals Handbook (The Materials Information Company, USA, 2001)

75. M. Jia and D. Zhang, Warm Compaction of Titanium and Titanium Alloy Powders, Titanium Powder Metall., 2015, p 183-200. doi:10.1016/B978-0-12-800054-0.00011-3

76. C.M. Lewandowski, N. Co-investigator, and C.M. Lewandowski, Powder Metal Technologies and Applications, Vol 7, ASM International, Materials Park, OH, 2015, p 2762 